\title{
UNA VISIÓN GLOBAL DEL MOVIMIENTO ASOCIATIVO VECINAL REGIONAL DURANTE LA TRANSICIÓN: 1970-1986
}

\author{
Constantino GonZALO MORELL \\ Universidad de Valladolid
}

\begin{abstract}
RESUMEN: Desde hace apenas veinte años la historiografía reconoce el importante papel opositor al franquismo del movimiento vecinal y le adjudica una relevante tarea: la formación ciudadana. En este artículo proponemos un repaso global al movimiento vecinal castellano y leonés, tanto a nivel de capitales de provincia como de federaciones así como los pasos de nuestros representantes a nivel nacional, con especial atención a los primeros movimientos conducentes a la creación de un ente federativo regional, la futura CAVE.
\end{abstract}

PALABRAS CLAVE: Asociación de Vecinos, Castilla y León, asamblea, encuentro, federación, Transición.

ABSTRACT: For just twenty years the historiography recognizes the importan role of opposition to Franco neighbourhood movement and ascribes an important task: citizen training. In this paper we propose a comprehensive review of the Castilian and Leonese neighborhood movement, both at the provincial capital of federations as well as the steps of our representatives at the national level, with special attention to the first movement leading to the creation of a federal agency Regionally, the future CAVE.

KEYWORDS: Neighborhood Association, Castilla y León, assembly, meeting, federation, Transition.

\section{INTRODUCCIÓN.}

El presente artículo intenta dar, por primera vez y desde el ámbito historiográfico, una visión global del desarrollo y principales logros del movimiento asociativo vecinal de nuestra Comunidad Autónoma ${ }^{2}$.

El movimiento asociativo vecinal es -desde no hace muchos años- reconocido como un actor importante para explicar el cambio político-social que supuso la transición de un sistema dictatorial a otro democrático, así como un agente

\footnotetext{
${ }^{1}$ Recibido el 21 de agosto y aceptado para su publicación el 13 de octubre de 2010.

${ }^{2}$ El presente artículo es fruto de la Tesis Doctoral, próxima a concluir: Movimiento vecinal y cultura política democrática en Valladolid: 1970-1986.
} 
democratizador -conocido es el concepto de escuela de ciudadanía que se le suele aplicar- pese a lo cual, son pocos los trabajos dedicados a su análisis y muchos menos aún los centrados en Castilla y León. Sirva este artículo para intentar cubrir esa laguna.

\section{UNAS CONSIDERACIONES URBANAS GENERALES.}

Hacia 1967, la primera ciudad de España era Madrid, con 2949801 habitantes, Valladolid ocupaba la $13^{\mathrm{a}}$ posición con 203011, Salamanca la $31^{\mathrm{a}}$ con 117540 y Burgos la $33^{\mathrm{a}}$ con 104034. La región tenía por esas fechas una de las más altas tasas de mortalidad infantil del país, lo que para los geógrafos es uno de los síntomas de subdesarrollo de una zona ${ }^{3}$, en nuestro caso, eminentemente agraria y rural. El encarecimiento de los costes salariales unidos a lo reducido de las explotaciones, a la congelación de los precios del trigo -el producto estrella del campo castellano- el dificultoso acceso a la mecanización y el grado de sobreexplotación familiar condujo a la inviabilidad de estas explotaciones y a la emigración masiva de la población rural ${ }^{4}$. De este modo entendemos el crecimiento de algunas de las capitales de provincia de la región.

Unas capitales que sufrieron con especial dureza los efectos del desarrollismo de los años sesenta. Para el arquitecto Fernando Chueca, los irresponsables administradores no tuvieron el mínimo cuidado de "estudiar al paciente para saber quién podía o quién no podía tolerar el tratamiento y se han quedado tan frescos haciendo ingerir una dosis de 12 plantas a una callecita de Soria como si fuera la Diagonal de Barcelona"s.

Este autor elaborará una escala para nuestra región "de descalabros producidos por el desarrollismo salvaje". Según esta y por orden alfabético, Ávila tendría un grado de deterioro urbanístico escaso, de índice 2; Burgos, de grado medio-grave e índice 5; León igual, pero de índice 6; Palencia ya tiene un grado de deterioro urbanístico grave, de índice 8; Salamanca de grado medio e índice 4; Segovia de grado leve e índice 2; Soria alcanza el grado de deterioro urbanístico máximo, con un índice de 10; Valladolid un grado muy grave de índice 9, compartido con Zamora, con un índice de 8 .

3 Datos extraídos de M. Fraga Iribarne; J. Velarde Fuentes y S. Del Campo Urbano (1972). La España de los años 70. Vol.1. La sociedad, Moneda y Crédito. Madrid: Banco Urquijo.

${ }^{4}$ L. J. PASTOR ANTOLín (1992). El proceso inmigratorio vallisoletano (1960-1985): factores, dinámica de flujos y estructura socio-profesional. Ponferrada: Junta de Castilla y León, p. 77. 54.

${ }^{5}$ F. Chueca Goitia, F. La destrucción del legado urbanístico español. Madrid: Espasa-Calpe, p. 
El grado de deterioro histórico-artístico, que es lo que evaluaba la escala ideada por este arquitecto, da una idea de las ciudades que crecieron y la medida en que lo hicieron. En nuestro trabajo hemerográfico encontramos un ejemplo de esto para León ${ }^{6}$.

Pero a parte del grave deterioro del patrimonio histórico-artístico, nuestras ciudades sufrieron en común la falta de planificación y de servicios en sus nuevos barrios. Así, problemas como el del leonés barrio de Pinilla lo encontraremos en toda la Comunidad: "las calles totalmente inundadas cuando llueve; barrizales durante todo el invierno; problemas con las inundaciones del Bernesga, polvo en el verano, en más de cien metros de calle únicamente una farola; ni una sola acera y grandes piedras y baches en sus calles. Y esto es solamente, lo que se puede ver en unos minutos de visita. Después, cuando se charla con los vecinos, empiezan a salir otros problemas. Escuelas, zonas verdes, parque infantil, iglesia, y sobre todo la incertidumbre de no saber dónde dirigir sus peticiones de auxilio" "?

\section{ASOCIACIONES DE VECINOS Y ASOCIACIONES DE CABEZAS DE FAMILIA.}

El 24 de diciembre de 1964, nace la Ley 191/1964 o lo que es lo mismo, la Ley de Asociaciones. Pero aunque en este trabajo hablemos de AA.VV., no podemos olvidar que lo que sancionaba el franquismo en 1964 es la aparición de Asociaciones de Cabezas de Familia, ligadas al Movimiento Nacional y dependientes de la Delegación Nacional de la Familia. A mediados de los años sesenta, una cierta apertura del régimen era vista como necesaria incluso para los más acérrimos franquistas, pensándose que una forma adecuada para ello sería la asociación de individuos a partir de la familia, uno de los pilares de la dictadura. Para ello se permitió que los residentes de un barrio se agruparan en una asociación en la que estuvieran los cabeza de familia, es decir, los hombres mayores de edad y eventualmente las mujeres casadas, una clara discriminación que no impidió a la mujer ser un elemento clave en el movimiento vecinal. Una asociación que en

\footnotetext{
6 "Aquí, en León, puede comprobarse la vigilancia que tiene la antigua fórmula disyuntiva de «renovarse o morir». La ciudad, nuestra ciudad, está cambiando de signo. La estampa urbanística de los barrios leoneses se está transformando radicalmente. Surgen edificaciones soleadas y nuevas por los cuatro puntos cardinales de la periferia urbana; ya se va dando en León el fenómeno de las grandes capitales. [...] Pero es que el fenómeno se repite también en el centro, en el mismo corazón del casco urbano. [...] El ritmo de la construcción en nuestra ciudad es sorprendente. [...]". (1964) "León, una ciudad que está naciendo. El cielo urbano se puebla de gigantescas grúas", Diario de León, martes 24 de noviembre de 1964, p. 9.

${ }^{7}$ L. F. MAYo (1975), «Los problemas de un barrio leonés. Los vecinos de Pinilla piden ayuda», Diario de León, 19 de julio de 1975, p. 11.
} 
principio, no debía representar ni mucho menos los intereses del barrio sino de las familias.

El desarrollo de los acontecimientos demostró a los legisladores franquistas que habían errado en su análisis, puesto que no sólo se erigieron como representantes de sus barrios sino que además, y al ser organismos legales, se erigieron como pantalla de los movimientos clandestinos opositores: sindicatos y partidos políticos.

El último matiz que debemos destacar es que todas las AA.VV. nacieron en los años 60 y 70 como Asociaciones de Cabezas de Familia, pero que no todas éstas desembocaron en una asociación de vecinos. Obviamente, las que permanecieron ligadas al Movimiento, tuvieron una vida efímera, mantenida por el régimen y corrieron su misma suerte.

\section{LAS ASOCIACIONES DE VECINOS A NIVEL REGIONAL.}

Ramón Suárez defendía para 1987 que Castilla y León era una de las regiones donde el movimiento vecinal se había extendido más, destacando el trabajo de la Federación de AAVV de Valladolid, que "ha ido poniendo en pie toda la coordinación castellano leonesa que, aunque con algunos baches, ha permitido reunir en varios encuentros autonómicos a la mayor parte de las federaciones existentes en esta autonomía". Todas las capitales de provincia contaban para esas fechas con federación de AAVV o estaban en trámites de hacerla, existiendo también federaciones o coordinadoras en Aranda de Duero (Burgos), Navas del Marqués (Ávila), Miranda de Ebro (Burgos), La Bañeza (León), Ponferrada (León), Medina del Campo (Valladolid) y Benavente (Zamora).

Aunque en los encuentros estatales habían participado alternativamente varias federaciones de esta región, como se puede observar en el cuadro final, Suárez destaca la Federación de Valladolid "con ponencias de gran profundidad en temas de administración local y, en menor medida, pero también con presencia constante la de Burgos",

Vamos a intentar analizar, provincia por provincia, la fortaleza o la debilidad de ese movimiento vecinal.

${ }^{8}$ R. SUÁREZ ClÚA (1987). «Situación del Movimiento Ciudadano en el Estado». En VV.AA. Espacio politico del movimiento vecinal y del consumerista en la España actual. Madrid: Fundación de Investigaciones Marxistas, p. 19. 


\subsection{Burgos.}

Para Burgos, Enrique Berzal destaca la asociación de la barriada de Illera ${ }^{9}$, aunque por el testimonio del líder vecinal burgalés Francisco Pérez sabemos que las más activas para el período de nuestro estudio eran las asociaciones de San Pedro de la Fuente (a la que pertenece desde 1979), la AAVV «Todos Unidos» de Gamonal, la de Vadillos y la de Fuentenueva ${ }^{10}$.

La AAVV de San Pedro de la Fuente aparece como asociación de cabezas de familia en 1976, siendo la tercera más antigua de Burgos. Sus primeras reuniones, como en otras asociaciones del momento se llevan a cabo en un bar -el Sevilla- y después en los locales de la parroquia. La primera acción reivindicativa será en defensa de los árboles del Paseo de Isla, amenazados de tala por el Ayuntamiento, a los cuales se encaraman los vecinos. Después se llevan a cabo campañas por una escuela digna seguida por otra por la inseguridad vial que produce la vía del tren, que termina con el corte de la misma ${ }^{11}$.

Otra nota significativa de esta asociación de vecinos burgalesa es que a instancias de la primera Junta de Castilla y León y en colaboración con ella, crean un antecedente de los actuales CEAS -Centro de Acción Social- que denominan UBAS -Unidad Básica de Acción Social- siendo pionera en ayuda a domicilio, colaborando a su vez con una cooperativa creada por la AAVV de Gamonal, otra de las importantes de Burgos $^{12}$.

En la provincia de Burgos, destaca Aranda de Duero, junto con Miranda de Ebro, una de las principales poblaciones burgalesas. En noviembre de 1976 nacía la AAVV del barrio de Santa Catalina de Aranda de Duero, que tendrá en sus inicios 250 socios (de una población de 7000 vecinos), que junto a otra AAVV de un polígono, eran las únicas asociaciones del período ${ }^{13}$.

\subsection{León.}

Enrique Berzal afirma que en 1970, los militantes de la HOAC de León crearon la primera asociación de vecinos de la provincia, la del barrio de Pinilla. Después

9 E. Berzal De La Rosa (2007). Sotanas rebeldes. Contribución cristiana a la transición democrática. Valladolid: Diputación Provincial de Valladolid, p. 141.

${ }^{10}$ C. GonZalo Morell (2007). Entrevista a Francisco Pérez, Burgos, 6 de noviembre de 2007.

11 Íbid.

12 C. Gonzalo Morell. Entrevista a Francisco Pérez...

13 (1978). «Asamblea de la Asociaciones de Vecinos del barrio de Santa Catalina», El Norte de Castilla, jueves 26 de octubre de 1978, p. 10. 
vendrían la del Ejido ${ }^{14}$, Mariano Andrés y San Mamés, a las que habría que sumar las de Trobajo del Camino y Villabalter ${ }^{15}$, pueblos del alfoz; pero sólo subsistirá desde la etapa precedente hasta la Transición la asociación vecinal del centro «León Típico» ${ }^{16}$, creada por vecinos y comerciantes ${ }^{17}$. Vemos así una primera característica del movimiento vecinal leonés y es que, aunque como en muchos otros puntos del país, sus primeras asociaciones nazcan al amparo de entidades o personalidades de la Iglesia, no perduran llegado el momento de funcionar autónomamente. Por eso aunque en el período que va de 1970 a 1977, se creen multitud de AAVV, actualmente las más antiguas que hayan tenido continuidad en el tiempo sean la ya referida del centro y la del barrio del Crucero $^{18}$, que data de 1983.

A la altura de 1977, el debate en la ciudad se centraba en los problemas de legalización que muchas AAVV encontraban. Así, las asociaciones de los barrios

14 “[...] -¿Cómo surgió la idea de hacer una Asociación?

-Hace año y medio se intentó hacer dos asambleas para dar los primeros pasos y formar una Asociación de vecinos. Esto era la consecuencia de una encuesta realizada entre 250 personas del barrio, cuya mayoría se habían pronunciado favorablemente sobre la necesidad de una asociación. Se constituyó una Comisión Gestora para crear una Asociación de acuerdo con el estatuto orgánico del Movimiento, es decir por medio de la Delegación Provincial de la Familia, y presentamos la documentación a últimos del mes de junio de 1976. [...]”. C. GALlEGO (1977). «Las Asociaciones de los barrios, a examen. El Ejido lucha por las zonas verdes», Diario de León, 23 de marzo de 1977, p. 12.

${ }^{15}$ E. BERZAL de LA Rosa (2007). Sotanas rebeldes... p. 140.

16 D. MARTínez PÉREZ (2004). Los movimientos sociales en la provincia de León durante la etapa inicial de la Transición: 1975-1977. León: Universidad de León, p. 191.

17 “... se pone en marcha la Asociación de Vecinos de León Típico, primero como núcleo comercial, y pronto con participación de particulares, amigos y cualquier persona interesada en los problemas del barrio y también en el principal acicate que planteaba: la protección, recuperación y conservación del casco antiguo de la ciudad de León”. O. FernándeZ Álvarez (1977). «La Asociación de Vecinos de León Típico. (La defensa de un barrio: vínculos de vecindad en el centro histórico de León)». León: Diputación Provincial de León, Instituto Leonés de Cultura, p. 132.

18 “Con la legalización de los correspondientes estatutos por el Gobierno Civil, hace poco más de una semana ha nacido en nuestra capital una nueva Asociación de Vecinos, denominada "Quevedo», correspondiente a los barrios del Crucero y La Vega, que agrupan un total de más de 20.000 habitantes.

De momento, la entidad cuenta con 25 socios fundadores, de entre los cuales días atrás fue elegida una Junta Directiva que la integran 18 personas. [...] La espoleta que indujo a los socios fundadores a crear esta Asociación vecinal, fue la polémica problemática surgida con ocasión de la iniciación y paralización de las obras de supresión del paso a nivel de la carretera de Zamora, en el barrio del Crucero. [...]". M. BAYONA (1983). «Acaba de nacer la nueva asociación de vecinos "Quevedo», de los barrios del Crucero y La Vega», Diario de León, domingo 30 de octubre de 1983, p. 5. 
de San José de las Ventas ${ }^{19}$, la Inmaculada y la Asunción, de San Francisco de la Vega, San Antonio de Padua y la Anunciación y la de San Mamés ${ }^{20}$ estaban en trámites, estando legalmente reconocidas la Asociación de Vecinos «León Típico», la Asociación Familiar del Barrio de Pinilla, la Asociación Familiar de San MartínEl Mercado, la Asociación Familiar de San Mamés-Santa Marina y la Asociación Familiar de San Claudio-Santa Ana"21.

En 1978 las asociaciones de vecinos de León convocan su primera manifestación conjunta, con el lema «Por un León mejor», "unas 2.000 personas participaron a última hora de ayer en la manifestación ciudadana convocada días atrás por diversas asociaciones de vecinos de León para urgir la solución a los problemas de equipamiento que padece la ciudad, así como para protestar por la gestión del Ayuntamiento en relación a estos problemas que se concretan -entre otros- en el abastecimiento del agua, transporte urbano, carencia de zonas verdes, centros sociales y limpieza de la vía pública. [...] habiendo participado en la marcha representantes de todas las asociaciones de vecinos de León, así como de diversas asociaciones vecinales de otras localidades de la provincia, como San Andrés del Rabanedo, Ponferrada, Astorga y La Bañeza, [...]”22.

Desde luego 2000 personas no parece una respuesta masiva ${ }^{23}$, pero hay que tener en cuenta que la ciudad tenía poco más de 100000 habitantes y que si se "consideran que otras capitales de envergadura similar a la nuestra han obtenido respuestas prácticamente similares en ocasiones como la del martes. De todos

19 “[...] -¿Cuándo comenzó a sentirse la necesidad de hacer una Asociación?

-Hace dos años pretendimos crear una asociación de barrio, ayudados por el padre Luciano (párroco de la Inmaculada) y se hicieron las asambleas para esto; no fructificó a causa de algunos problemas. [...]”. C. GALLEGo (1977). «Las Asociaciones de los barrios, a examen. Las Ventas, Asunción e Inmaculada unidos por problemas comunes», Diario de León, 20 de marzo de 1977, p. 20.

20 “[...] En este barrio existen dos asociaciones: La Asociación de Vecinos del Barrio de San Mamés (en trámite) y la Asociación Familiar de San Mamés. [...]." Una asociación familiar que ya no existía más que de nombre. C. GALlEGO (1977). «Las asociaciones de los barrios, a examen. La Asociación de Vecinos de San Mamés (en trámite), de su legalización», Diario de León, 16 de marzo de 1977 , p. 12.

${ }^{21}$ (1977). «Defectos jurídicos de algunas Asociaciones de Vecinos», Diario de León, 23 de marzo de 1977 , p. 14.

${ }^{22}$ M. BAYONA (1978). «Con el lema "Por un León mejor", y convocados por las asociaciones de vecinos. Unas 2000 personas participaron en la manifestación para protestar por los problemas de la ciudad», Diario de León, 21 de junio de 1978, p. 12.

23 H. Álvarez Vega; T. SARmiento García y D. Martínez Pérez. El desarrollo de la oposición política a través de la problemática laboral leonesa: 1962-1975. Universidad de León, León, 2006. 
modos, nos dijeron, no se esperaba una respuesta mucho mayor, y prueba de ello es que al solicitar la autorización gubernativa, se estimó una participación de 2.000 a 3.000 personas.

Para las Asociaciones de Vecinos, las razones de la respuesta obtenida responden a que el ciudadano de León no se suele mostrar partidario de secundar las manifestaciones, entre otros motivos porque siguen con miedo a este tipo de muestras reivindicativas. Otra razón de la escasa participación la estiman en que las propias asociaciones no llevaron a cabo debidamente a nivel de base la campaña de participación y concienciación" 24 .

Unas asociaciones vecinales que variaban mucho en su número de socios, desde los 370 de la AAVV de «Mariano Andrés» de Las Ventas a los 102 de la AAVV de El Ejido. Las propias asociaciones reconocían que el índice de afiliación era escaso entre los vecinos, "principalmente por la actitud reacia de los vecinos a participar, y el poco «rodaje» que tienen diversas asociaciones vecinales" ${ }^{\text {"25 }}$. Demasiado optimista quedaba la estimación de un dirigente vecinal, cuando un periodista le pidió hacer una estimación de los socios que podía tener en un futuro próximo su asociación y éste respondió que sobre los $8000^{26}$.

La segunda característica del movimiento vecinal leonés es su ligazón con el comercio; es decir, al menos tres de sus AAVV nacerán como asociaciones de vecinos y comerciantes: «León Típico», San Martín-El Mercado ${ }^{27}$ y El Crucero. Esta característica no la hemos encontrado en ninguna otra AAVV del país y puede ser un rasgo distintivo leonés, aunque para ser sinceros, pese a que nacieran con la doble vocación, con el paso del tiempo se decantaron más por los vecinos que por los comerciantes o dejaron de funcionar.

La tercera característica es la dificultad para coordinar a nivel de ciudad las actividades de las asociaciones de León. A fines de 1976 aparece el primer intento

24 M. BAyona (1978). «Autocrítica de las Asociaciones de Vecinos a los resultados de la manifestación del martes», Diario de León, 22 de junio de 1978, p. 12.

${ }^{25}$ M. BAYONA, (1978). «Autocrítica de las Asociaciones...», p. 12.

${ }^{26}$ R. (1977). «Defender los intereses del barrio y "sanearlo" moralmente», La Hora Leonesa, sábado 12 de febrero de 1977, p. 7.

27 “-Quisiera que me aclarara una cuestión. ¿La asociación de San Martín-Mercado es una asociación de vecinos o de comerciantes?

-Es una asociación de vecinos primordialmente. Lo que pasa es que está apoyada por los comerciantes para defender el León típico. Y sus intereses, por supuesto. [...]”. M. E. CuEvAs (1977). «El objetivo del concurso fotográfico es promocionar el León típico y la fotografía de los aficionados», Diario de León, 7 de abril de 1977, p. 13. 
de crear un ente interasociativo. Las AAVV y de familia de San Francisco de la Vega, San Antonio de Padua y la Anunciación, San Claudio, El Ejido, San Mamés, Ventas-Inmaculada-Asunción y El Crucero "constituyeron una «Coordinadora» de Asociaciones de Vecinos que a finales de marzo visitó al Gobernador Civil para conocer los errores en la documentación presentada",28. Una coordinadora que según Berzal tuvo una vida efímera.

Será ya en la década de los ochenta cuando la idea de crear una entidad que coordinara a las diferentes asociaciones leonesas cobre vida. Primero se intentará desde la provincia: "según estaba previsto se celebró el pasado sábado, a las 6 de la tarde en la Biblioteca Pública Municipal, una reunión de asociación de vecinos de la provincia, al objeto de formar la Federación Provincial de Asociaciones de Vecinos. A la misma habían sido invitadas 37 asociaciones, de las cuales asistieron 12. De Astorga estuvieron «La Unión» y «Los Arrieros» de San Andrés. Se formó una comisión gestora, siendo el presidente el que lo es actualmente de «Bedunia», de La Bañeza; podría llevar por nombre «Caminantes», siendo aprobados también sus Estatutos que elevarán a instancias superiores"29. Finalmente, la Federación nacerá en 1986.

Al igual que ocurre en el caso de Burgos, León cuenta con un movimiento vecinal fuerte en la provincia, porque al contrario que en Valladolid, ambas cuentan con varias poblaciones grandes a parte de la capital de provincia.

Así, Astorga y la capital del Bierzo, Ponferrada, contarán con un destacado movimiento ciudadano.

En Astorga la Asociación de Vecinos de los barrios de San Andrés-Santa Clara «Los Arrieros ${ }^{30} »$ será la pionera, seguida poco después por la Asociación de Vecinos del barrio de Rectivía «Los Peregrinos ${ }^{31} »$.

28 D. MARTíneZ PÉREZ (2004). La transición democrática leonesa: 1975-1977. León: Universidad de León, p. 50.

29 A. DEL Río SÁnCheZ (1983). «Creada la Asociación Provincial Asociaciones de Vecinos», La Hora Leonesa, martes 4 de octubre de 1983, p. 11.

30 “"...] -¿Cuándo se creó la A. de V. «Los Arrieros»?

-La Asociación de Vecinos «Los Arrieros» se fundó en el año 1977, más concretamente nuestros estatutos tienen fecha de 10 de noviembre del citado año, [...]". A. DEL Río SuÁREZ (1981). «Julio García Prada, presidente A.V. "Los Peregrinos"”, La Hora Leonesa, viernes 6 de noviembre de 1981, p. 10.

31 “-¿Cómo nació la Asociación de Vecinos en Rectivía?

-Hay que atribuirlo a la falta de un órgano representativo a nivel de barrio, que pudiera hacerse eco de las necesidades del mismo, y animados también por la existencia de las otras dos Asociaciones 
Las asociaciones de Astorga, tras "las juntas celebradas en Valladolid y La Bañeza sobre Federación de Asociaciones. Así como de la de Astorga, celebrada el sábado", votarán en 1983 en contra de "integrarse en la Federación Provincial de Asociaciones de Vecinos, siendo el resultado de 14 votos en contra, 2 a favor y 5 abstenciones" ${ }^{32}$.

En Ponferrada, la prensa ya en 1971 se quejaba amargamente de que "en nuestra ciudad no tenemos asociaciones de vecinos. ¿Es que los habitantes de Ponferrada son más difíciles de unir que los de otros lugares? no creemos que ocurra tal cosa, [...] Si tenemos en cuenta, además, que las asociaciones de vecinos se preocupan por los actos culturales, por la juventud, por las zonas verdes y deportivas, por las guarderías, en suma: por una vida más humana dentro de la cada día más inhabitable ciudad, podemos concluir que quizá sea ésta una de las soluciones que estamos necesitando aquí, uno de los oasis que precisa el desierto ponferradino. [...] Lo que estamos dilucidando es la carencia de unos interlocutores válidos para el diálogo entre Ayuntamiento y vecinos de los diferentes barrios que se ven atosigados de problemas, sin encontrar solución -no por no haber intentado solucionarlos- y quizá tengamos que pensar que el fallo de todo esto es la carencia de esos interlocutores. [...] Por desgracia vamos a remolque también en esto de las asociaciones de vecinos, que tienen que venir formadas desde abajo -esto es, por los vecinos-. Pueden estar seguros éstos de que los órganos oficiales no van a promover la constitución de asociaciones de vecinos porque, entre otras cosas, las asociaciones de vecinos de hoy en día nos son agrupaciones cómodas de hombres amorfos. Son una forma de incorporar a la lucha por una vida más humana en las ciudades, a todos los vecinos" $" 33$.

Sin embargo no será hasta 1978 en que aparezca el movimiento vecinal en Ponferrada, de la mano de la Asociación Familiar «Matagal ${ }^{34}{ }$ ) del barrio de

de Vecinos, «La Unión»y «Los Arrieros», un grupo de vecinos decidimos promoverla. Esto fue allá por el mes de diciembre, y desde entonces se ha venido operando en plan de Junta Gestora Provisional para realizar todos los trámites burocráticos que han sido necesarios hasta su reciente aprobación. [...]". A. DEL Río SÁNCHEZ (1978). «"Los Peregrinos", nueva Asociación de Vecinos de Astorga», Diario de León, 6 de mayo de 1978, p. 15.

32 A. Del Río SÁnchez (1983). «Asamblea de la Asociación de Vecinos «Los Peregrinos» de Rectivía», La Hora Leonesa, martes 4 de octubre de 1983, p. 11.

${ }^{33}$ R. L. TemeZ (1971). «¿Por qué no tenemos asociaciones de vecinos?», Diario de León, 24 de julio de 1971, p. 14.

34 “[...] -Historia de la Asociación en dos palabras.

-En marzo de 1977 un grupo de entusiastas constituyen la Junta Promotora de la Asociación con 14 miembros. Estos redactan los estatutos y se preocupan de ir captando socios. [...] Al cabo de un año, febrero del presente año, el gobernador civil aprueba los estatutos de la Asociación. En ese 
Cuatrovientos y la Asociación de Vecinos «Pajariel» de Flores del Sil ${ }^{35}$, seguida en 1980 de la Asociación de Vecinos «Los Olivares»", que confirma el deseo de "que en el más breve plazo posible, se pueda constituir una Coordinadora de Asociaciones de Vecinos, que aunen sus esfuerzos solidarios en bien de toda la población sin discriminación de barrios, solicitando a todos los vecinos que, como ciudadanos conscientes y responsables se organicen en sus respectivas asociaciones, única forma de mejorar las condiciones de vida en la ciudad y profundizar en las relaciones sociales" ${ }^{37}$.

\subsection{Palencia.}

La primera AVV de Palencia será la de la barriada del Cristo del Otero ${ }^{38}$, hacia 1976.

La primera movilización nos la relata el líder vecinal palentino Abel Alonso: "con motivo de la romería, que es una romería general, que arrojan pan y queso... con motivo de aquello se hizo una acción que consistía en grandes pancartas en la imagen del Cristo del Otero que se repartían durante la noche... una serie de cosas reivindicando... luz, aceras, alcantarillado, pues toda una serie de estructuras del que el barrio carecía entonces. Esa fue la primera asociación, a partir de ahí se creó... hubo una protesta que se devolvió cuando tiraron las autoridades el pan y el queso, los vecinos devolvían el pan y el queso al alcalde, que fue una pedrea un tanto a la inversa, de la más insólita que ha habido. Ahí arrancó esa asociación y a partir de ahí el resto de barrios fueron tomando conciencia y de alguna manera se fue encendiendo...."39.

Del año 81 es la Asociación de Vecinos del barrio de Pan y Guindas, a la que pertenece el propio Alonso y es una de las más importantes de Palencia.

momento eramos ya 450 socios. [...]". I. LinARES. (1978). "Ante las fiestas de Cuatrovientos. Denuncia pública de la Junta Directiva de la Asociación de Vecinos "Matagal"», Diario de León, Decano de la prensa leonesa, 28 de abril de 1978, p. 16.

35 I. LinARES (1978). «Elegida la Junta directiva de la Asociación de Vecinos «Matagal». Captación de socios y estatutos de la Asociación «Pajariel»”, Diario de León, 28 de febrero de 1978, p. 15.

36 (1980). "Bierzo. Constituida la Junta Directiva de la asociación de vecinos "Los Olivares"», Diario de León, 22 de agosto de 1980, p. 15.

37 (1980). «Bierzo. Constituida la Junta...», p. 15.

38 E. BerZAL DE LA Rosa (2007). Sotanas rebeldes..., p. 142.

${ }^{39}$ C. Gonzalo Morell (2008). Entrevista a Abel Alonso, Palencia, 15 de diciembre de 2008. 
La Federación de AAVV de Palencia se crea en 1989, coordinando el trabajo no sólo de las AAVV de la capital, sino también de algunas localidades de la provincia, como Guardo, Revilla de Pomar, etc ${ }^{40}$.

\subsection{Salamanca.}

Para Salamanca, Berzal señala que "desde 1971, los hoacistas de esta localidad participan activamente en la creación de las Asociaciones de Vecinos de San José, Chamberí-Los Alambres (aquí cobraron especial protagonismo la Orden de los Capuchinos)", a las que habría que sumar las de Pizarrales, La Prosperidad y Garrido $^{41}$.

Cuando a fines de 1976 los vecinos del salmantino barrio de Chamberí, "reunidos en asamblea provocada por los acontecimientos de los días 22 y 23 de octubre, decidieron descubrir cuántas personas ajenas se habían infiltrado entre ellos, sólo encontraron una: un policía de paisano, que abandonó el recinto entre los aplausos de los reunidos... Quedaba así rotundamente desmentida la afirmación del gobernador civil de la provincia, que se había escudado en el viejo tópico de «los grupos que manipulan»y en otras razones igualmente pintorescas, para prohibir una manifestación solicitada con todos los requisitos legales. [...] la asamblea decide marchar hacia la plaza [Mayor] en la mañana del sábado día 23. La policía toma el recinto con antelación, aleja a grupos solidarios de otros barrios salmantinos y copa los tres puentes sobre el Tormes que constituyen el único acceso de Chamberí a la ciudad"42. Chamberí se convierte de este modo en la AVV más activa de Salamanca en el período.

FEVESA, la Federación de Vecinos de Salamanca nacerá ya acabando la década de los ochenta.

\subsection{Soria.}

"Especialmente peligrosa por su potencial peligrosidad era, según informes gubernativos de los años 60, la barriada soriana de Juan Yagüe, [...]." En estos términos se refiere Enrique Berzal cuando habla de Soria analizando la conflictividad social. La AVV del barrio de Yagüe es creada en 1975, siguiendo a este autor, por la presidenta de la HOAC local, tras llevar a cabo un cuestionario al modo de Las Delicias en Valladolid- sobre la situación del barrio y sus

\footnotetext{
40 Íbid.

${ }^{41}$ E. Berzal De La Rosa (2007). Sotanas rebeldes... p. 140.

42 Colectivo De Información. (1976). «Un barrio encerrado». Triunfo $N^{o} 719$, p. 43.
} 
carencias, que el PCE intentará monopolizar ${ }^{43}$. Aunque como expone el acta, la asociación nace en febrero de 1976, siendo la primera AVV Soriana, como AVV Barriada de Yagüe, denominación que posteriormente se modifica por AVV Juan Yagüe, llamándose en la actualidad Asociación de Vecinos, Consumidores y Usuarios La Barriada.

Ya en 1984 ampliará su estructura abriendo un centro de cultura, para la tercera edad y para la juventud.

La Federación Provincial de AVV de Soria se crea en 1988 a instancias de la AVV de Yagüe, que además ocupa su presidencia hasta 2003, así como la de la entidad asociativa regional CAVECAL, de 1989 en que nace hasta $1993^{44}$.

\subsection{Valladolid.}

La ciudad de Valladolid aglutina -en nuestra opinión- el movimiento vecinal más fuerte y cohesionado de la región, siendo el que mayor continuidad ha tenido desde sus orígenes. El nacimiento del asociacionismo vecinal en la capital del Pisuerga se sitúa en febrero de 1970, cuando las autoridades dan por buenos, finalmente, los estatutos de la Asociación de Cabezas de Familia del barrio de la Rondilla de Santa Teresa, la actual Asociación Vecinal Rondilla. Después vendrán la de Las Delicias, Belén y Pilarica, siendo a la altura de 1977 cuando aparece el grueso de asociaciones, aunando esfuerzos en una Coordinadora Interbarrios de vida efímera, sustituida por la actual Federación Provincial de AVV de Valladolid, que nace en 1982.

Por la falta de espacio para desarrollar el movimiento vecinal de esta ciudad y porque ya lo hemos tratado en anteriores ocasiones, nos remitimos a trabajos previos ya publicados o en vías de publicación ${ }^{45}$, aunque no podemos dejar de

43 E. BERZAL De La Rosa (2007). Sotanas rebeldes... p. 141.

44 Asociación de Vecinos La BARRiada. (2010). Historia, [recurso electrónico] http://www. labarriada.org/ [Consultado: 25-3-2010].

${ }^{45}$ C. GONZALO MORELL:

-(2008). «La aportación del movimiento asociativo vecinal a la cultura democrática de la Transición en Valladolid. Los vecinos contra la dictadura». En Aldunate, O. (coord..). I Encuentro de Jóvenes Investigadores en Historia Contemporánea de la AHC. Zaragoza: Universidad de Zaragoza.

-(2010). «Los vecinos contra todos: La conflictividad vecinal en el tardofranquismo y la Transición (1964-1986)». En CARRASCO, A. (ed.). Conflictos y sociedades en la Historia de Castilla y León: aportaciones de jóvenes historiadores. Valladolid: Universidad de Valladolid. 
destacar la importancia del movimiento vecinal de la ciudad como núcleo aglutinante de la oposición y como catalizador de las principales movilizaciones sociales $^{46}$.

\subsection{Zamora.}

Zamora será junto con Valladolid la pionera del movimiento vecinal en Castilla y León. Es en Zamora donde aparece la primera asociación, aunque como ocurre en el caso de Las Delicias, será con una forma asociativa totalmente ajena a la vecinal.

Es en el barrio de San José Obrero, hacia 1966 cuando aparece la Asociación de Desarrollo Comunitario, "un subterfugio para poder obtener el respaldo económico de la Iglesia. Esta barriada obrera era considerada peligrosa por las autoridades, pues en ella se concentraban supuestos peligros comunistas. La presencia de unos cuantos curas-rojos y la voluntad del vecindario suponen una experiencia cristianomarxista del estilo de la vivida en La Pilarica en Valladolid" ${ }^{, 7}$. Y es significativa esta referencia a La Pilarica porque como en el barrio vallisoletano, será la llegada de tres nuevos curas la que cambie la situación en el barrio ${ }^{48}$.

El concepto de Desarrollo Comunitario tenía por objetivo integrar a los jóvenes, a los matrimonios y a los ancianos en el ejercicio de la solidaridad a través de la prestación de trabajo y tiempo de forma espontánea y al contrario que los movimientos de cristianos de base, era una idea de la propia jerarquía de la Iglesia.

-(2010). «Cuando los vecinos cuestionan el sistema: La decisión de la Asociación Familiar Delicias». En Fuentes NAvarro, Ma Candelaria; Contreras BeCerra, Javier y LóPez Chaves, Pablo (eds.). II Encuentro de Jóvenes Investigadores en Historia Contemporánea. Granada: Universidad de Granada.

-(2009). «Los barrios frente al Ayuntamiento: las difíciles relaciones entre las autoridades municipales y las Asociaciones de Vecinos de Valladolid en la Transición, 1973-1986». En QuirosA, R. (ed.). Actas IV Congreso Internacional de $H^{a}$ de la Transición en España: Sociedad y movimientos sociales. Almería: Universidad de Almería.

-«Las asociaciones de vecinos versus el sistema: Las trabas a la acción vecinal en la Transición vallisoletana». (Próximo a publicar).

-«La aportación del movimiento asociativo vecinal al lenguaje de la Transición en Valladolid: 1975-1985». (Próximo a publicar).

${ }^{46}$ Desde la petición de dimisión de uno de los últimos alcaldes franquistas a la lucha por plazas escolares, contra los planes parciales o los impuestos abusivos.

${ }^{47}$ B. Llamero (2001). «Caminos de Libertad o la Transición Inconclusa. El caso de San José Obrero». En J.M. Francia (coord.). Caminos de libertad: La Transición en Zamora. Salamanca: Caja Duero, pp. 18-19.

${ }^{48}$ F. AntÓn (2001). «San José Obrero: el barrio del presidente». En Francia, J. M. (coord.). Caminos de libertad... p. 98. 
En Zamora tomará forma organizando conferencias y actividades culturales, deportivas y recreativas autogestionadas y creando además una Asociación de Padres $^{49}$, para colaborar con los centros escolares ${ }^{50}$.

Gracias a la mediación de los curas de la parroquia de San José, los vecinos obtienen un préstamo de la Iglesia para adquirir una finca de "16000 metros cuadrados -la famosa «JOSA»- donde convivir, debatir y, más adelante, celebrar reuniones clandestinas, además de organizar campamentos para jóvenes de los que luego nacería una especie de ayuntamientos democráticos cuyos cargos se elegían por votación". Su primer éxito como asociación será hacer llegar al Ayuntamiento a su candidato a las elecciones por el tercio familiar de la democracia orgánica franquista ${ }^{51}$.

Contará con unos 500 socios hacia 1970 y como promotor y primer presidente, al futuro presidente de la Comunidad Autónoma, el hoacista y ugetista Demetrio Madrid $^{52}$.

Será ésta AVV la que organice la primera manifestación en Zamora ${ }^{53}$, después de cuarenta años de dictadura, exigiendo el vallado de una avenida donde se habían sucedido los atropellos así como otra serie de mejoras para el barrio ${ }^{54}$.

El Norte de Castilla recogía la noticia de la siguiente manera:

"Resultó curioso contemplar los rostros de los que veían la primera manifestación de su vida. [...] Y las reivindicaciones que el barrio de San José ha lanzado no son tan sencillas como «parques, jardines, que niños hay a miles» o el simple «Los barrios unidos, jamás serán vencidos».

[...] Está claro que las reivindicaciones, no sólo afectan al barrio de San José Obrero, sino a otros muchos puntos de la ciudad (y si no, ahi están las pancartas de Pinilla, Sepulcro y Olivares, que no por pequeños no son

${ }^{49}$ En el barrio de San José Obrero existía la AVV y una Asociación de Padres que Demetrio Madrid presidió en distintas épocas. Formalmente eran independientes y tenían sus matices en cuanto a aspiraciones pero trabajaban estrechamente juntas. C. GonZalo Morell (2007). Entrevista a Demetrio Madrid López, Valladolid, 12 de diciembre de 2007.

50 D. MAdRID LÓPEZ (2001). «Reflexión desde la izquierda (1974-1982)». En FrAnCIA, J. M. (coord.). Caminos de libertad... p. 79.

${ }^{51}$ C. GonZalo Morell (2007). Entrevista a Demetrio Madrid...

52 E. BERZAL De La Rosa (2007). Sotanas rebeldes... p. 125.

53 “[...], en una travesía del barrio, a la que acudió mucha gente del resto de la ciudad y la provincia". C. GonZalo Morell (2007). Entrevista a Demetrio Madrid...

54 B. Llamero (2001). «Caminos de Libertad...», p. 19. 
dignos de atender), ni las reivindicaciones sólo afectan al problema de circulación [falta de semáforos] ",55.

Estas muestras del poder reivindicativo sumadas a la presión que ejercerá la asociación sobre el Ayuntamiento para terminar unas obras en el barrio da a la barriada de San José Obrero la imagen "para las autoridades locales algo así como la oposición para el Gobierno español"

A finales de 1976 nace la AVV del barrio de Olivares ${ }^{57}$, seguida un año después por la de Espíritu Santo ${ }^{58}$ y las de la Alberca, Los Bloques, Pinilla, Ramiro Ledesma y la barriada de Asturias un poco después ${ }^{59}$.

\subsection{Segovia y Ávila.}

Respecto a Segovia, presuponemos que si no la más antigua, la AVV de San Lorenzo debe ser de las asociaciones veteranas del movimiento vecinal segoviana, pues en abril de 1977 ya publicaba su boletín «Nuestro Barrio» ${ }^{60}$.

El 23 de febrero de 1984, los representantes de las AAVV de San Marcos, San Lorenzo, San Millán, La Albuera y San José daban vida a la Federación Provincial de Asociaciones de Vecinos de Segovia ${ }^{61}$.

En cuanto a Ávila, es la única provincia de la región sobre la que no hemos obtenido noticia sobre movimiento vecinal alguno en el período de 1970-1986, con lo que presuponemos que sus AAVV fueron muy tardías, algo explicable, quizá, por el escaso crecimiento de la ciudad abulense, pues crecimiento, densificación y problemas de urbanismo son el caldo de cultivo clásico para que aparezca una

55 C. Pedrero (1976). «El eco de una manifestación», El Norte de Castilla, martes 7 de septiembre de 1976, p. 7.

${ }^{56}$ C. Pedrero (1976). «Vuelve el conflicto en el barrio de San José. Las obras tenían que haber terminado el día 29 de octubre», El Norte de Castilla, martes 9 de noviembre de 1976, p. 8.

57 C. Pedrero (1976). «Aprobada la Asociación de Vecinos del barrio de Olivares. Será la segunda en la capital», El Norte de Castilla, miércoles 17 de noviembre de 1976, p. 8.

${ }^{58}$ C. Pedrero (1977). «Constante auge del movimiento de barrios», El Norte de Castilla, sábado 5 de febrero de 1977, p. 8.

59 (1977). «Auge de los movimientos ciudadanos», El Norte de Castilla, viernes 9 de septiembre de 1977 , p. 5.

60 (1977). «"Nuestro barrio”, boletin de los vecinos de San Lorenzo», El Norte de Castilla, martes 19 de abril de 1977 , p. 9.

${ }^{61}$ M.G. (2009). «Veinticinco años de todos y para todos», El Adelantado de Segovia, lunes 9 de noviembre de 2009. 
AAVV y en Ávila esto no se ha dado hasta fechas recientes. Una explicación aplicable a otros muchos puntos de nuestra Comunidad Autónoma.

\section{LAS RELACIONES ENTRE LAS AAVV DE CASTILLA Y LEÓN.}

Debido al propio desarrollo y crecimiento del movimiento vecinal en la región y a medida que aparecen las diferentes entidades federativas o coordinadoras provinciales, nace el sentimiento de aunar esfuerzos y compartir experiencias. Los encuentros a nivel nacional y sobre todo, el trabajo realizado por la Federación de AVV de Valladolid será el comienzo de una relación entre las distintas asociaciones de Castilla y León. Ángel Ceballos nos lo relata así:

"Sí, las relaciones con otras asociaciones de Castilla y León. [...] teníamos unas capacidades e incluso recursos económicos por el convenio único que se hizo en su día con el Ayuntamiento, que nos suponían unos ingresos totales, pues para tratar de crear y organizar un movimiento asociativo en Castilla y León, tanto de ciudad como de zonas rurales y la primera convocatoria la hicimos en, yo recuerdo que en Tordesillas",62.

Demetrio Madrid, desde su experiencia en Zamora, afirma que su ciudad no estaba aislada, pues existía cierta coordinación a nivel regional, "pero no por ninguna organización sino más bien a nivel de contactos personales, favorecidos por la circunstancia de que éramos siempre los mismos" ${ }^{63}$. Personas entre las que habría que destacar al líder vallisoletano Juan Cornejo ${ }^{64}$.

Al ser Valladolid la Federación más consolidada y con más experiencia organizativa, será esta entidad la que promueva los dos primeros encuentros regionales; ninguno de ellos, curiosamente, se celebrará en la capital.

Tordesillas, localidad muy cercana a Valladolid y muy bien comunicada por carretera, es el punto elegido para muchos encuentros autonómicos de entidades bien diversas, desde partidos políticos a ecologistas y será el punto de arranque de los contactos del movimiento vecinal de Castilla y León ${ }^{65}$. de 2008.

62 C. GonZalo Morell (2008). Entrevista a Ángel Ceballos Buendía, Valladolid, 3 de diciembre

${ }^{63}$ C. GonZalo Morell (2007). Entrevista a Demetrio Madrid ...

64 "Juan Cornejo ya había tenido una experiencia anterior, muy amplia, moviéndose por todo el territorio nacional. Él, con la compañera suya que también le gustaba, se iban los dos de un lado para otro... aquello les instruyó”. C. GonZAlo Morell (2008). Entrevista a Ángel Ceballos...

65 "Para entablar contactos y analizar esta situación tuvo lugar el pasado fin de semana en nuestra ciudad una reunión entre representantes vecinales de Zamora y Valladolid. Anteriormente se habían 
De esta forma, el domingo 17 de abril de 1983 se celebraba el I Encuentro de Asociaciones de Vecinos de la comunidad autónoma castellano-leonesa. En total, asistieron noventa y dos delegados que representaban a asociaciones de vecinos de Navas del Marqués (Ávila), El Hornillo (Ávila), Ávila, Aranda de Duero (Burgos), Burgos, Cistierna (León), La Bañeza (León), Astorga (León), León, Guardo (Palencia), Palencia, Nava de Béjar (Salamanca), Vitigudino (Salamanca), Salamanca, Aldealuenga de Pedraza (Segovia), Segovia, Medina del Campo (Valladolid), Valladolid, Benavente (Zamora) y Zamora, "mientras que mandaron adhesiones las de Miranda de Ebro (Burgos), Onamio (León), Turrubuelo (Segovia) y Villacastín (Segovia)". Todas las provincias de la región estuvieron representadas salvo Soria, "de ahí que en la mesa del Encuentro figurasen ocho personas" ${ }^{\prime 66}$.

Aprobado el orden del día, a propuesta de la Federación de Valladolid, "cada una de las entidades presentes expuso las actividades que desarrolla; el nivel de organización en el que se mueve y sus relaciones con las instituciones locales. Todas ellas expresaron su carácter reivindicativo, sobre todo en temas de urbanismo y de equipamientos colectivos, mientras que varias denunciaron las actuaciones de las respectivas Corporaciones municipales de sus localidades porque «tienden a desarticular el movimiento vecinal por su carácter crítico»»"67.

Poco después se desarrolla el segundo encuentro, en la segunda población más importante de Valladolid, Medina del Campo ${ }^{68}$. Gracias a las ayudas municipales ${ }^{69}$, en el mes de agosto la Federación de Valladolid pudo "remitir información sobre el Encuentro a todas las Asociaciones de Vecinos de la región, así como diverso material básico sobre asociacionismo vecinal", intentando que cada provincia

celebrado conversaciones entre vallisoletanos, palentinos y burgaleses...”. (1983). «Federación Regional de Vecinos», El Norte de Castilla, martes 22 de febrero de 1983, p. 8.

66 (1983). «Noventa y dos delegados asistieron al primer encuentro castellano-leonés de asociaciones de vecinos», El Norte de Castilla, martes 24 de mayo de 1983, p. 12.

67 (1983). «Noventa y dos delegados asistieron...», p.12.

68 "Se vio la cosa que era positiva. [...] Tuvimos la malauvada de pedir el castillo. Entonces el castillo no se hacían actividades, todavía lo tenían lo que eran los residuos de la Sección Femenina. Todavía vivía Nuria, que era la que desde los años 40 había sido la directora de aquello. Eso era increíble y nos recluimos tres días sobre la conveniencia de seguir adelante...”. C. GONZALO MORELL (2008). Entrevista a Ángel Ceballos...

69 "En resumen, los encuentros han supuesto bastante esfuerzo en organización y dinero, que ha tenido que afrontar la organización que en este momento está en mejor posición de salida, como es la de Valladolid”. (1983). «El próximo fin de semana se celebrarán el II Encuentro Regional. La Organización Regional, un reto para las asociaciones de vecinos», Hoja del Lunes, 31 de octubre de 1983, p. 9. 
contara con unos diez representantes, equilibrando las asociaciones del medio rural con las urbanas ${ }^{70}$.

En noviembre de 1983, unos cien representantes de unas ochenta asociaciones de pueblos y ciudades de Castilla y León se reunieron ${ }^{71}$, debatiendo en torno al orden del día propuesto por la delegación de Valladolid y aprobado en la asamblea, que desarrolló tres ponencias:

1. Ecología y medio ambiente en la región, desarrollada por la Federación de AAVV de Valladolid.

2. Relaciones de las Asociaciones de Vecinos con las instituciones locales provinciales y autonómicas ${ }^{72}$, desarrollada por la AVV «Todos Unidos», de Burgos.

3. Participación de los vecinos en la solución de sus problemas, por la Federación de AAVV de Zamora.

"Los debates tuvieron altura y en algunas ponencias se comprobó la existencia de opiniones encontradas, pero siempre existió el diálogo. Estas diferencias eran inevitables debido a que no puede ser igual la realidad vecinal en unas zonas rurales y poco pobladas que la de grandes ciudades con un amplio movimiento obrero", ${ }^{\text {? }}$.

Concluido el segundo encuentro regional, se intenta que los siguientes se desarrollen en otras provincias que no sean Valladolid y que sean otras federaciones las que los organicen.

De este modo, el tercer encuentro se desarrollará en Zamora, en 1984, en el que "a lo largo de las dos sesiones plenarias y de las 2 reuniones de las comisiones de trabajo se debatirán tres ponencias: «Por un urbanismo más humano», presentada por la Federación de Palencia; «Salud pública y sanidad en Castilla y León»,

70 (1983). «En el Castillo de la Mota el 5 y 6 de noviembre. II Encuentro de asociaciones de vecinos de Castilla y León», Hoja del Lunes, 18 de julio de 1983, p. 8.

71 (1983). «Clausurado el II Encuentro Regional», Hoja del Lunes, 7 de noviembre de 1983, p. 6.

72 (1983). «En el Castillo de la Mota el 5 y 6 de noviembre. II Encuentro de asociaciones de vecinos de Castilla y León», Hoja del Lunes, 18 de julio de 1983, p. 8.

73 (1983). «Las asociaciones de vecinos hacia la unidad regional», El Norte de Castilla, miércoles 9 de noviembre de 1983, p. 7 
elaborada por la Federación de Valladolid, y «Participación vecinal en la gestión municipal», presentada por la Federación de Zamora" ${ }^{74}$.

El problema llegará en el cuarto encuentro, que decide desarrollarse en León, pero que "no pudo realizarse, por la falta de infraestructura de las AA. de VV. de León y la apatía del resto de las provincias" "75 , lo que pone fin a esta fórmula de encuentros, que demuestra que es una forma de relación acabada. La solución era crear un organismo a nivel regional. Se estaban siguiendo, a escala, los mismos pasos que a nivel nacional. De organizar los primeros encuentros entre asociaciones se pasa a construir un ente aglutinador. "El gran reto es la consecución de una organización regional que aglutine a los vecinos de Castilla y León, como el interlocutor válido ante el poder constituido". Una Federación Regional de AAVV de Castilla y León; un reto que asume la Federación Provincial de AAVV de Valladolid en el XIV Encuentro Nacional, en Madrid en enero de $1983^{76}$.

Pese a que el proyecto aparece a inicios de la década de los ochenta, no será hasta finales de la misma en que tome cuerpo. De este modo y ya en 1989, las Federaciones de AAVV de Aranda de Duero, Burgos, Ponferrada, Salamanca, Soria, Segovia, Palencia, Valladolid y Zamora ${ }^{77}$, elaborarán los estatutos de la Confederación de Asociaciones de Vecinos de Castilla y León (CAVECAL) y decidirán, tras profundos debates ${ }^{78}$ internos, que sea Valladolid quien se haga cargo

74 (1984). «Las AA.VV. tomarán medidas contra el recargo municipal», El Norte de Castilla, domingo 3 de junio de 1984, p. 22.

75 I. CRISTÓBAL (secretaria). (1986). Acta de la Asamblea Anual Ordinaria y Extraordinaria de la Federación Provincial de Asociaciones de Vecinos de Valladolid. Valladolid: Acta del 9 de febrero de 1986, p. 2.

76 (1983). «El próximo fin de semana se celebrarán el II Encuentro Regional. La Organización Regional, un reto para las asociaciones de vecinos», Hoja del Lunes, 31 de octubre de 1983, p. 9.

77 "La asamblea general extraordinaria de la Federación de Asociaciones de Vecinos de Valladolid decidió confederarse con las otras doce federaciones que hay constituidas en los municipios de más de veinte mil habitantes de Castilla y León, es decir, las de las nueve provincias más las de Aranda de Duero, Miranda de Ebro y Ponferrada [...] el proyecto de estatutos elaborado por la Federación de Aranda de Duero...”. R.R.V. (1989). «Los vecinos de Valladolid formarán parte de una confederación regional», El Norte de Castilla, domingo 19 de noviembre de 1989, p. 17.

${ }^{78}$ Francisco Pérez, presidente de la Federación de AAVV de Burgos, tendrá varios roces con José Miguel Gutiérrez, por su personalismo. Según él, el representante de Pajarillos quería contratar una secretaria para la futura CAVECAL -presidida en principio por Burgos, con Secretaría en Valladolidy llega a engañar a la delegación burgalesa haciéndoles creer que la Confederación ya estaba legalizada. Parece ser que el asunto se descubrió cuando el turno de presidencia pasó a Soria, que la legalizó finalmente. Además hubo serias discusiones en el momento en que CAVECAL debió elegir 
de la Secretaría que vele por el proceso de consolidación de la entidad en sus primeros $\operatorname{pasos}^{79}$.

Para Demetrio Madrid, Valladolid era una ciudad más y el problema no se encontraba en el personalismo de sus dirigentes o en sus intentos de controlar la nueva entidad, sino en "la extraordinaria extensión de nuestra comunidad"

Para José Miguel Gutiérrez, las relaciones con otras asociaciones de vecinos de Castilla y León fueron malas. Además, la región "es muy de derechas" y los intentos por levantar una organización regional han fracasado, constituyendo CAVECAL un islote, un ente que "va a su bola" Carmen Quintero: "yo creo que no funcionan, a nivel regional el movimiento vecinal no funciona, porque nosotros hemos pertenecido durante unos cuantos años, como federación, a la CAVECAL [...] y la verdad es que hemos terminado saliéndonos porque es una merienda de negros y hay asociaciones que no tienen ningún interés político" ${ }^{" 82}$.

Desde la perspectiva de Palencia, Abel Alonso, que participó directamente en las primeras reuniones representando a su federación, afirma que "las relaciones son buenas entre las distintas asociaciones, lo que pasa es que, a veces, hay que redefinir bastante el papel de las federaciones regionales o el papel del asociacionismo a nivel regional, porque donde más encontramos nuestra razón de ser es en el ámbito local, donde es más claro el papel que cumple. Cuesta más ver cuál es el objetivo..., ${ }^{, 83}$.

Ángel Ceballos defiende que "siempre ha habido intención de contactos, de hacer algo permanente, pero las dificultades son notables, porque para mantener una cosa de esta, los temas de reuniones tienen que ser constantes, del intercambio de ideas y este tipo de estructura regional, no tienes capacidad económica, ni los núcleos humanos están a la altura adecuada. [...] Ya cuesta, cuesta mucho... el trabajo es ímprobo, al principio era partidario de ello, pero luego, llegó un

un delegado ante la CAVE. Parece ser que salió elegido Pérez frente a Gutiérrez. C. Gonzalo Morell (2007). Entrevista a Francisco Pérez...

${ }^{79}$ F.M. «Las Asociaciones de Vecinos de Castilla y León se constituirán en Confederación». p. 10.

${ }^{80}$ C. Gonzalo Morell (2007). Entrevista a Demetrio Madrid...

${ }^{81}$ C. GonZalo Morell (2008). Entrevista a José Miguel Gutiérrez de Diego, Valladolid, 11 y 12 de marzo de 2008.

${ }^{82}$ C. GonZalo Morell (2009). Entrevista a Carmen Quintero Gallego, Valladolid, 24 de febrero de 2009.

${ }^{83}$ C. GonZalo Morell (2008). Entrevista a Abel Alonso... 
momento, en que personalmente no lo veía tan claro porque suponía merma de efectivos propios, dificultades para el intercambio de ideas, dificultades para la elaboración de documentos y propuestas [...]". Porque "ese trabajo que sería muy interesante a nivel regional y nivel estatal, pues es muy difícil y aquí una y otra vez, una y otra vez se insiste pero no termina de cuajar porque hay que darlo continuidad. Tiene que haber unos cuadros... y lo demás, para verse cada seis meses..." ${ }^{84}$.

El análisis de la CAVECAL excede, como el de la propia CAVE, los límites temporales de nuestro estudio, pero no por ello debemos dejar de hacer constar una traba que ha lastrado a ambas: la dificultad del movimiento asociativo vecinal para superar el ámbito localista del barrio, cuna y razón de ser del mismo.

\section{LAS RELACIONES DE LAS AAVV DE CASTILLA Y LEÓN CON SUS HOMÓLOGAS NACIONALES.}

Gran parte del peso de la representatividad de la región caerá en la Federación de AAVV de Valladolid, debido a la fuerza de su movimiento vecinal, su "temprana" unión en federación y el estar presente en gran parte de los encuentros a nivel nacional -ver cuadro final- lo que supone que Valladolid sea la sede elegida para celebrar el XIII Encuentro Estatal de AAVV del Estado Español, el 5 y 6 de junio de 1982. Un Encuentro celebrado bajo el título Balance y Análisis de las Asociaciones de Vecinos: Perspectivas de Futuro. En Valladolid se reúnen en el Colegio San Viator más de ochenta personas ${ }^{85}$ representando a asociaciones y federaciones de Albacete, Astorga, Burgos, Elda (Alicante), Gerona, Logroño, Madrid, Málaga, Murcia, Palencia, Palma de Mallorca, Pamplona, Sabadell (Barcelona), Sagunto (Valencia), Santander, Sevilla, Toledo, Valencia, Vigo y Zaragoza. Siendo significativas las ausencias tanto de Barcelona como de Bilbao ${ }^{86}$, aunque ésta última delegue en la representación de Pamplona.

Los acuerdos más importantes que toma la asamblea son:

$\checkmark$ Rechazar el ingreso del país en la estructura belicista de la Organización del Tratado del Atlántico Norte (OTAN).

${ }^{84}$ C. GonZalo Morell (2008). Entrevista a Ángel Ceballos...

85 (1982). «Las Asociaciones de Vecinos elaborarán un manifiesto que recoja la filosofía del movimiento ciudadano», Hoja del Lunes, 7 de junio de 1982, p. 5.

86 Federación de AAVv de VAlladolid (1982). Las Asociaciones de Vecinos, hoy. XIII Encuentro Estatal de Asociaciones de Vecinos. Valladolid: 5-6 junio 1982. Valladolid: Federación de AAVV de Valladolid, p. 2. Biblioteca Universidad de Valladolid, Carpeta 268/27. 
Ante las sentencias del juicio por el reciente Golpe de Estado del 23 de febrero, manifestar "su total disconformidad con la mayor parte de las sentencias a los implicados", pues la asamblea defiende "la petición del máximo rigor en las penas".

Denunciar la tortura, y exigir la derogación de la Ley de Seguridad Ciudadana.

Frente a los planes nucleares del Gobierno, se posicionan en contra de la apertura de la Central Nuclear de Lemoniz, y se declara la "firme oposición al Plan de Nuclearización en el Estado Español, concretado en el Plan Energético Nacional, por lo que supone en una sociedad ya de por sí suficientemente contaminada, peligrosa y militarizada" ${ }^{" 87}$.

El diario El País recogía la noticia en estos términos:

"El certamen, al contrario de los anteriores, tuvo carácter monográfico ya que únicamente se abordó un tema: balance y análisis de las asociaciones de vecinos y perspectivas de futuro. La base de las discusiones fue una ponencia de dieciocho folios elaborada por Valladolid [...]. Los asistentes no llegaron a acuerdos respecto a la constitución de una federación estatal. Como sustitutivo aprobaron la creación de una secretaría estable formada por Burgos, Sabadell, Málaga, Madrid, Sevilla, Valladolid y Zaragoza, que se encargará de coordinar y distribuir información y preparar el próximo encuentro, previsto para los días 4 y 5 de diciembre en Madrid. En este nuevo certamen es posible que se aborde más profundamente la constitución de un organismo estatal y que se presente el manifiesto sobre el movimiento ciudadano. A lo largo de las dos jornadas del XIII Encuentro fueron aprobadas casi todas las mociones presentadas, excepto una contra la represión en Euskadi que fue retirada por entenderse que sus peticiones ya estaban incluidas en la condena de la práctica de la tortura y en el rechazo a la ley de seguridad ciudadana, ${ }^{, 88}$.

La secretaría compartida se simplifica a fines de 1986, recayendo en exclusiva

\footnotetext{
${ }^{87}$ Moción aprobada por los votos de las delegaciones de Pamplona, Burgos, Sabadell y La Rioja. Federación de Aavv de VAlladolid (1982). Las Asociaciones de Vecinos, hoy. XIII Encuentro ... p. 10. Biblioteca de la Universidad de Valladolid, Carpeta 268/27.

88 (1982). «Las asociaciones de vecinos se consideran imprescindibles para desarrollar la democracia». El País, martes 8 de junio de 1982. Biblioteca de la Universidad de Valladolid, Carpeta $268 / 27$.
} 
en la Federación de Valladolid ${ }^{89}$, que es elegida en la Asamblea Estatal celebrada en Mérida como Secretaría Permanente de la Coordinadora ${ }^{90}$. Es el premio a un esfuerzo continuado por representar a Valladolid y cuando no acuda ninguna asociación regional más, a Castilla y León, como en la I Asamblea de la Coordinadora Estatal de Asociaciones de Vecinos llevada a cabo en Toledo, donde la asamblea "aprobó por unanimidad la ponencia sobre la Ley de Bases, defendida por Valladolid a partir del trabajo común desarrollado por Castilla y León en el Encuentro Regional celebrado en Zamora" ${ }^{" 91}$ o en la II Asamblea, celebrada en Sevilla, donde "los representantes de nuestra capital presentarán una importante propuesta de resolución sobre la situación de las haciendas locales. Juan Cornejo, presidente de la federación de asociaciones de vecinos, José Miguel Gutiérrez de la asociación de los Pajarillos, Carmelo Pozas de la Pilarica y Ángel Ceballos de la Rondilla, serán los representantes vallisoletanos..." ${ }^{\text {92 }}$.

Poco después se decide dar el paso de crear una entidad con mayor fuerza y presencia que esta Coordinadora Estatal, el propio Ceballos lo resume así: "cuando llegaron, «vamos a tener que trabajar como locos, como enanos», y efectivamente. Yo personalmente no encontraba ni horas para tratar de organizar. Trataba de conseguir informaciones para la asamblea constituyente, que era la siguiente, en Puertollano..." ${ }^{93}$.

Pero constituida la Confederación de Asociaciones de Vecinos de España -o del Estado Español- lo cierto es que la organización "tuvo su vida pero yo, para mí, entró en una dinámica de recursos, de profesionales, de captación de recursos, [...], a la hora de la verdad, si no se tiene un control muy fuerte sobre ello... se

89 ،

“... en un momento determinado se dijera que había que constituirse no ya como un núcleo pero reconocido, registrado, aquello fue la Confederación de Asociaciones de Vecinos. Además ocurrió que el XIII Encuentro Estatal -que entonces eran encuentros estatales- fue en Valladolid (yo creo que se hizo una ponencia muy interesante, por lo menos de la necesidad, de la historia del movimiento ciudadano, un documento muy amplio... pues eso lo chupamos entre dos o tres) y ya el XIV encuentro, que debió ser en Mérida o algo así se vinieron con la sorpresa que habían decidido constituirse y que había que estructurarlo y que como Valladolid daba mucho tal, Valladolid se constituyó como la primera Secretaría estatal. Sólo fue un año”. C. GonZalo MorelL (2008). Entrevista a Ángel Ceballos...

90 Federación de AAVV de VAlladolid. (2005). 25 Años haciendo ciudad 1980-2005. Valladolid: Federación de Asociaciones de Vecinos de Valladolid, p. 11.

91 (1984). «La Coordinadora Estatal de Vecinos rechaza la Ley de Bases de Régimen Local». El Norte de Castilla, jueves 5 de julio de 1984, p. 5.

92 (1983). «II Asamblea estatal de Asociaciones de Vecinos», El Norte de Castilla, sábado 10 de diciembre de 1983, p. 5.

93 C. Gonzalo Morell (2008). Entrevista a Ángel Ceballos... 
empezaron a producir, al parecer, porque nosotros no lo vivimos, aquello entró en una deriva de cargos remunerados... es lógico tener una infraestructura, pero sabiendo hasta dónde se puede llegar y no permitir que aquello se nos escapase de las manos. Pues aquello se escapó y la dinámica de justificación de recursos... el no tener dinero da problemas y el tenerlo infinitamente más. Lo que podría haber sido un elemento de dinamización de los movimientos vecinales, pues a la hora de la verdad no cuajó, pero no cuajó por eso, por falta de transparencia del sistema y por una cierta organización monolítica. Y estamos lo mismo que te decía con la regional. $\mathrm{O}$ se están reuniendo de continuo, intercambiando y orientando o... se trabaja muy pegado al suelo o esto no termina de tirar adelante. La CAVE, que ahora se trata de revitalizar, yo ya no me meto tanto, estoy apartado, pero no termino de verlo claro" ${ }^{94}$. Su compañera de asociación -Rondilla- Carmen Quintero apostilla que "tenía mucha relación y generalmente he ido por parte de la Federación a todas las reuniones que había de la CAVE que trataban algún tema social o educativo. También me gustaba mucho... de Galicia también había movimiento vecinal bastante fuerte y la CAVE concentraba a todos esos movimientos. A mí me parece que en los años que la CAVE funcionó, funcionaba muy bien, porque aglutinaba a todo el movimiento vecinal. Después hubo problemas económicos y unos líos internos, que desapareció, pero la verdad es que a mí me dio mucha pena que desapareciera la CAVE, porque creo que aglutinaba bastante al movimiento vecinal y además daba mucho empuje". Además, "cuando ibas a una reunión de la CAVE, venías siempre con ganas de trabajar, con ganas de seguir luchando. Yo creo que fue un movimiento muy interesante a nivel estatal, que dio mucho... fue una pena que desapareciera y fue una pena que desapareciera también por problemas internos, que siempre, ya sabes cómo somos los seres humanos, a veces hay desavenencias y zancadillas y cosas que hacen que una cosa que funciona muy bien vaya a pique justo por esto..." ${ }^{\text {. }}$.

\begin{tabular}{lcc}
\multicolumn{3}{c}{ Relación de reuniones a nivel estatal y federaciones asistentes de la región ${ }^{96}$ : } \\
\hline \multicolumn{1}{c}{ Evento } & Año y lugar & Representantes de Castilla y León \\
\hline I Encuentro & 1977, Madrid & León, Salamanca y Valladolid \\
II Encuentro & 1977, Valencia & \\
III Encuentro & 1978, Murcia & Astorga
\end{tabular}

94 C. GonZalo Morell (2008). Entrevista a Ángel Ceballos...

${ }^{95}$ C. GonZalo Morell (2009). Entrevista a Carmen Quintero...

${ }^{96}$ Únicamente los representantes de las AAVV de L'Horta (Valencia) y Cornellá asistirán a todas las reuniones a nivel estatal. Federaciones como las de Álava o Gijón sólo acudirán a dos. Establecidas las Asambleas en 1983, Valladolid, Madrid, Barcelona y Valencia serán las únicas capitales de provincia en acudir a todas. A la primera asamblea de la CAVE, en 1987, acudirán también la Federación de la Comarca de El Bierzo, Segovia y Soria. 


\begin{tabular}{lll} 
IV Encuentro & 1978, Zaragoza & \\
V Encuentro & 1979, Barcelona & \\
VI Encuentro & 1979, Málaga & \\
VII Encuentro & 1979, Bilbao & Burgos \\
VIII Encuentro & 1980, Madrid & Burgos \\
IX Encuentro & 1980, Sabadell & Burgos \\
X Encuentro & 1980, Sevilla & Valladolid \\
XI Encuentro & 1981, Valencia & Burgos y Valladolid \\
XII Encuentro & 1981, Zaragoza & Burgos y Valladolid \\
XIII Encuentro & 1982, Vallad. & Astorga, Burgos, Palencia, Valladolid y Zamora \\
XIV Encuentro & 1983, Madrid & Burgos, Palencia y Valladolid \\
I Asamblea & 1983, Valencia & Valladolid \\
II Asamblea & 1983, Sevilla & Burgos, Palencia y Valladolid \\
III Asamblea & 1984, Toledo & Burgos, León, Salamanca y Valladolid \\
IV Asamblea & 1985, Córdoba & Burgos y Valladolid \\
V Asamblea Extraord. & 1985, Cádiz & Valladolid \\
VI Asamblea & 1985, Barcelona & Burgos, Miranda de Ebro y Valladolid \\
VII Asamblea & 1986, Puertoll. & Salamanca y Valladolid \\
\hline
\end{tabular}

Tabla de confección propia a través de los datos extraídos de la obra: GUERRERO CASTRO, M. (1998). Veinte años de encuentros y desencuentros de las Asociaciones de Vecinos. Madrid: CAVE, pp. 7-9.

\section{CONCLUSIONES.}

A lo largo de este trabajo hemos intentado reflejar la evolución del movimiento asociativo vecinal, desde sus orígenes hasta la consolidación de los Ayuntamientos democráticos, aplicando primero una óptica local para pasar después a otra de conjunto para intentar dar una idea global de los esfuerzos que cientos de vecinos de nuestra Comunidad realizaron para intentar cambiar las realidades de sus barrios. Porque no podemos nunca olvidar que aunque existan entidades supraasociativas, como lo son las Federaciones y las Confederaciones, el sentido primero y último de una asociación de vecinos es lo que ya en $1977 \mathrm{Javier}^{\mathrm{a}}$ Berriatua definió como el interés vecinal . Un interés vecinal que, pese a nacer en un barrio concreto, encuentra todo su sentido en una lucha a nivel de ciudad cuando no de región o a nivel nacional, puesto que el problema de un barrio es, muchas veces, el problema de la vida urbana misma. Ello es lo que ha justificado desde sus orígenes la creación de una entidad regional, al igual que una entidad nacional, que recogiera y diera fuerza y voz común a los problemas de las barriadas de España, hijas de las deficiencias del desarrollismo franquista. 